\title{
Mapping Turnaround Times (TAT) to a Generic Timeline: A Systematic Review of TAT Definitions in Clinical Domains
}

\author{
Bernhard Breil ${ }^{*}$, Fleur Fritz ${ }^{\dagger}$, Volker Thiemann ${ }^{\dagger}$ and Martin Dugas
}

\begin{abstract}
Background: Assessing turnaround times can help to analyse workflows in hospital information systems. This paper presents a systematic review of literature concerning different turnaround time definitions. Our objectives were to collect relevant literature with respect to this kind of process times in hospitals and their respective domains. We then analysed the existing definitions and summarised them in an appropriate format.

Methods: Our search strategy was based on Pubmed queries and manual reviews of the bibliographies of retrieved articles. Studies were included if precise definitions of turnaround times were available. A generic timeline was designed through a consensus process to provide an overview of these definitions.

Results: More than 1000 articles were analysed and resulted in 122 papers. Of those, 162 turnaround time definitions in different clinical domains were identified. Starting and end points vary between these domains. To illustrate those turnaround time definitions, a generic timeline was constructed using preferred terms derived from the identified definitions. The consensus process resulted in the following 15 terms: admission, order, biopsy/examination, receipt of specimen in laboratory, procedure completion, interpretation, dictation, transcription, verification, report available, delivery, physician views report, treatment, discharge and discharge letter sent. Based on this analysis, several standard terms for turnaround time definitions are proposed.
\end{abstract}

Conclusion: Using turnaround times to benchmark clinical workflows is still difficult, because even within the same clinical domain many different definitions exist. Mapping of turnaround time definitions to a generic timeline is feasible.

Keywords: Turnaround time, hospital information systems, cycle time, process time, timeline

\section{Background}

Health care processes are difficult to define because of their complexity [1]. Assessing time definitions in clinical processes can help to analyse workflows in hospital information systems (HIS) and to identify weak points [2]. Due to increasing costs in health care it is important to improve the efficiency of clinical workflows.

When analysing process times, it is important to be aware of the different definitions used for time intervals. One of the most common measures of laboratory or pathological services is the turnaround time (TAT)

\footnotetext{
* Correspondence: bernhard.breil@ukmuenster.de

† Contributed equally

Institute of Medical Informatics, University of Münster, Domagkstraße 9, 48149 Münster, Germany
}

which has frequently been used since 1980 to quantify the time for laboratory tests in an objective manner [3]. The first reference dates from 1971 and describes TAT as the time interval between electrocardiogram printing and placement of the printout in the patient chart [4]. In the laboratory workflow TAT is an important indicator of performance [5] and is even seen as a "necessary condition for (...) trust between patient and physician" [6].

Publications about report TAT in radiology workflow [7], TAT for processing medication orders [8] or patient cycle time [9] demonstrate that these process indicators are not limited to pathology or laboratory services. These parameters can be used for HIS monitoring and benchmarking especially with respect to process descriptions and assessments. However, in the available literature 
many different definitions for TAT are used. Starting and end points for specific processes depend on several factors such as hospital departments (e.g. laboratory, pathology, emergency department), analysed subjects (e.g. patients, specimens), included activities and priority, which all result in varying points in time and also different units of measurement from seconds over hours to days.

On the one hand TAT, for example, can be defined as "time from receipt of the specimen" until "time of availability of the result" (laboratory TAT) [10] as well as "time from the physician's request" until the "time the physician views the result" (total TAT) [11]. On the other hand there are the drug turnaround time [12] and medication TAT [13], which describe the same time interval. Being a common problem not only in medicine, those parameters are used as synonyms and homonyms. Using different TATs is reasonable to measure and evaluate certain aspects and systems, but only if they are precisely defined. Fuzzy definitions and the use of synonyms and homonyms make it difficult to compare processes between hospitals. In this context we conducted a literature review to detect similarities as well as varieties in order to facilitate benchmarking.

Most of the previous literature reviews regarding TAT are focused on laboratory or pathological departments. Manor had analysed literature concerning TAT in clinical laboratories from 1989 until 1999 to evaluate methods in order to improve the processes in clinical laboratories [14]. At that time she compared pneumatic tubing systems with decentralized testing, satellite laboratory, point-of-care testing and computer technology. Currently, most processes are supported by computer technology. This is the reason why Georgiou and Westbrook analysed only computerised physician order entry systems (CPOE) in their literature reviews of 2006 $[15,16]$. They assessed the general impact of CPOE and focused on the three phases of pathological services "preanalytical", "analytical" and "postanalytical", while comparing designs and results of recent articles. However, this review is also limited to pathological services and does not include other process time definitions like drug TAT or time for diagnosis. Another literature review, concerning computerization, analysed general time efficiency as a result of the use of electronic health record [17]. In his review of laboratory TAT in 2007 Hawkings reveals the different steps of a testing cycle from ordering to interpretation and action. He states that data for extra-laboratory activities are needed, because often non-analytical delays are prolonging the total TAT [5].

In a recent review [18] Schimke compared central laboratory testing to point of care testing and argues that there is only limited potential for further shortening of the intra-laboratory TAT. Increased patient benefit can only be achieved by earlier clinical decisions, based on the results which require better integration of preand post-analytical phases (ultimately point of care testing). In one of the latest publications in this field TAT was compared while assessing the impact of CPOE systems on clinical workflow [19].

There is a vast range of literature concerning TAT for pathological and laboratorial services, which focus on design of CPOE systems, results, usability and quality effects. There are also papers in which the domains are overlapping, for example, when laboratory point of care testing was performed in the emergency department to improve their workflow $[20,21]$. However, the literature concerning not only process analyses but containing also precise definitions of process indicators in various domains is limited. The purpose of this paper is to review TAT definitions, which are used to analyse clinical workflows in different medical domains in order to measure effects of the use of information technology.

Our objectives in this review are to:

1) collect relevant literature concerning process times in clinical workflows,

2) analyse the existing TAT definitions and the related domains and

3) summarise these TAT definitions and map them to a generic timeline.

\section{Methods}

\section{Constraints}

The term information system in our analysis is constrained to clinical information systems with a direct impact to an electronic health record. Therefore we did not include systems which are primarily used for billing, enterprise resource planning or data warehousing. Consequently, the considered groups of users are hospital staff and patients. We did not distinguish processes for inpatients and outpatients, as generic TAT definitions are very similar, for example regarding laboratory processes.

\section{Literature collection}

A literature review was carried out to summarise process time indicators in studies having been published until 31.12.2009. The main search was based on the Medline database via Pubmed [22]. In addition, the reference lists from relevant articles and additional articles by key authors were also reviewed. Three reviewers with previous scientific experience in HIS and clinical processes selected and reviewed all papers $(\mathrm{BB}, \mathrm{FF}, \mathrm{VT})$. The decision about including or excluding a paper in our analysis was based on consensus discussion.

We experimented with several query approaches (for example MeSH-terms like "process assessment (health 
care)/methods" or free text "process time"). As these queries resulted in a great amount of hits, which proved to be very unspecific, we identified the term "turnaround time" to be the most specific search criterion.

Our approach was to search for the term "turnaround time" in title and abstract. Then we limited the results to those having an abstract. We removed all papers not written in English or German. As our main interests were the effects of the use of information technology, we further removed those not being related to the use of computerised systems and those with a strong biological and/or medical focus (for example new laboratory test methods).

During the full text review we removed all papers that did not include process time definitions and we added relevant papers found through a review of referenced publications. This process is also illustrated in Figure 1.

\section{Analysis process}

The resulting relevant articles were reviewed according to process indicators, related to time in different medical domains. We grouped them into those having a time definition with starting and end points and those having relevant aspects but no precise definitions. From the first group we extracted information about the short and long text of the definitions, the starting and end points of the process indicators, the units of the measured time, the domains and the year of publication. This information was aggregated in a separate list of definitions, keeping the original articles as references. Articles from the second group were used for background information.

\section{Summarizing definitions}

We collected information about TAT definitions concerning their abbreviations, starting and end points as well as measured time units (days, hours and minutes). In order to depict these TATs a suitable timeline is needed. As TAT intervals usually span over different points in time, we selected the most commonly used and best defined terms for corresponding points in time

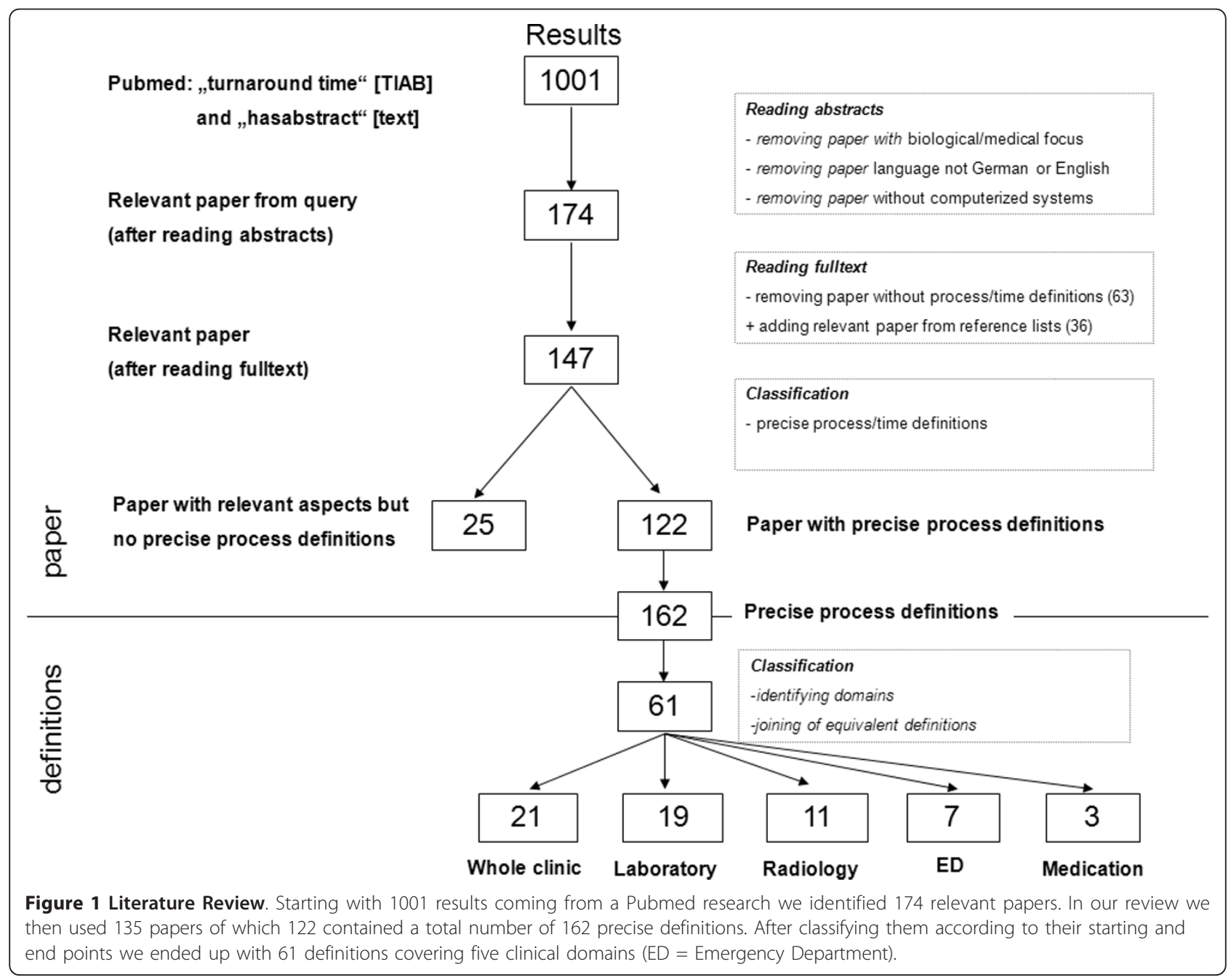


through a consensus process. For example, in a study by Ramaswamy the report turnaround time (RTAT) includes four steps [23]. Based on our harmonisation, a timeline was designed to bring all identified process times in a sequential order and to show which steps are included.

\section{Results}

\section{Collection and analysis process}

As illustrated in Figure 1 the PubMed search resulted in 1001 publications about TAT. After reading the abstracts and removing those not relevant according to our inclusion criteria, 174 publications were left, 63 of which were removed after having read the full text and another 24 were added as a result of reviewing reference lists of key articles. The remaining 135 articles were agreed upon by all three reviewers to be relevant with respect to our aim. Thirteen of them did not contain precise enough definitions of the starting and end points of the process and were therefore not classified in the list of definitions. Out of the other 122 articles all relevant information according to our analysis strategy was extracted and resulted in 61 definitions of TAT [24-145]. Many of these measures were not precisely specified and had to be deduced from the context. To classify the resulting definitions, we chose the following five different clinical domains, which we considered being appropriate for our further analysis: laboratory, radiology, medication, emergency department and whole clinic. The domain "whole clinic" contains processes of different departments such as operation theatre. Most definitions were therefore found in the domain whole clinic (21) followed by definitions concerning laboratory (19), radiology (11), emergency department (7) and medication (3). The full table with all definitions and their references can be found in the supplement (see Additional file 1).

\section{Summarizing TAT definitions}

While analysing and collecting TATs we identified terms which range from admission to the final report after discharge. Some expressions were used synonymously for starting and end points (e.g. "biopsy" and "sampling"). In total, we identified 15 points in time regarding the description of the process independent from the respective user, although some are predominantly relevant for TATs in a specific domain (e.g. "receipt of specimens in laboratory" in a laboratory).

Although there are some processes which start before the patient is admitted to a hospital, we chose admission as the first starting point, as it is rather difficult to measure pre and post clinical times. We considered the admission as a synonym for the term hospitalization as well as for the arrival at a department. The next step after admission is typically the anamnesis in which the physician orders or requests a service. This service may be the examination of the patient or the starting point of anaesthesia and an operation procedure. In a laboratory context this examination can be a biopsy (also called the collection of specimen/sampling) and in radiology the examination can be the radiography. After the examination, which ends with the patient or physician leaving the operation/examination room, the specimen reaches the laboratory. This point in time is relevant in a laboratory context and very often measured and documented in the laboratory information system (LIS). The next commonly described point in time is the completion of the procedure or examination. In a laboratory context this is the time, when a result is available. This can be considered similar to the completion of an X-ray or any imaging procedure, which is completed and has to be interpreted in the next step. This interpretation ends when a first diagnosis or result is available. Dictation and transcription (which is a synonym for typing) are commonly used in radiology, whereas verification or reviewing of the preliminary results is also done in laboratories and other domains. The next important step is the availability of the report, in many cases containing the finalized and verified diagnosis, which is then delivered back to the requester. This point in time ranges from the delivery of a report to the arrival of blood components or medications. In some papers the time when viewing the delivered report was also considered as a relevant step. Then following is the treatment (similar terms: patient treatment or appropriate treatment), for instance drug administration. At the end of the process chain we identified patient discharge, which is similar to a transfer to another department or location, e.g. arrival in the operation theatre. The final report is often sent after discharge and documented in the information system; so we included the final reports as our last point in time. Table 1 shows the results of the consensus process to design a generic timeline for all TAT definitions derived from our literature review.

\section{Turnaround times in different clinical domains Domain "Laboratory"}

In the laboratory domain we identified 19 different TATs starting from the arrival in an emergency department to the reporting of the results and ending with the ordering of a form to the final report. The most common definition is the laboratory TAT beginning with the receipt of a specimen in a laboratory until the availability of the result, which was measured in 25 articles of this review. In 9 articles times were measured from the ordering of the results to their posting. Most references started from the order or from the receipt in the 
Table 1 Preferred Terms

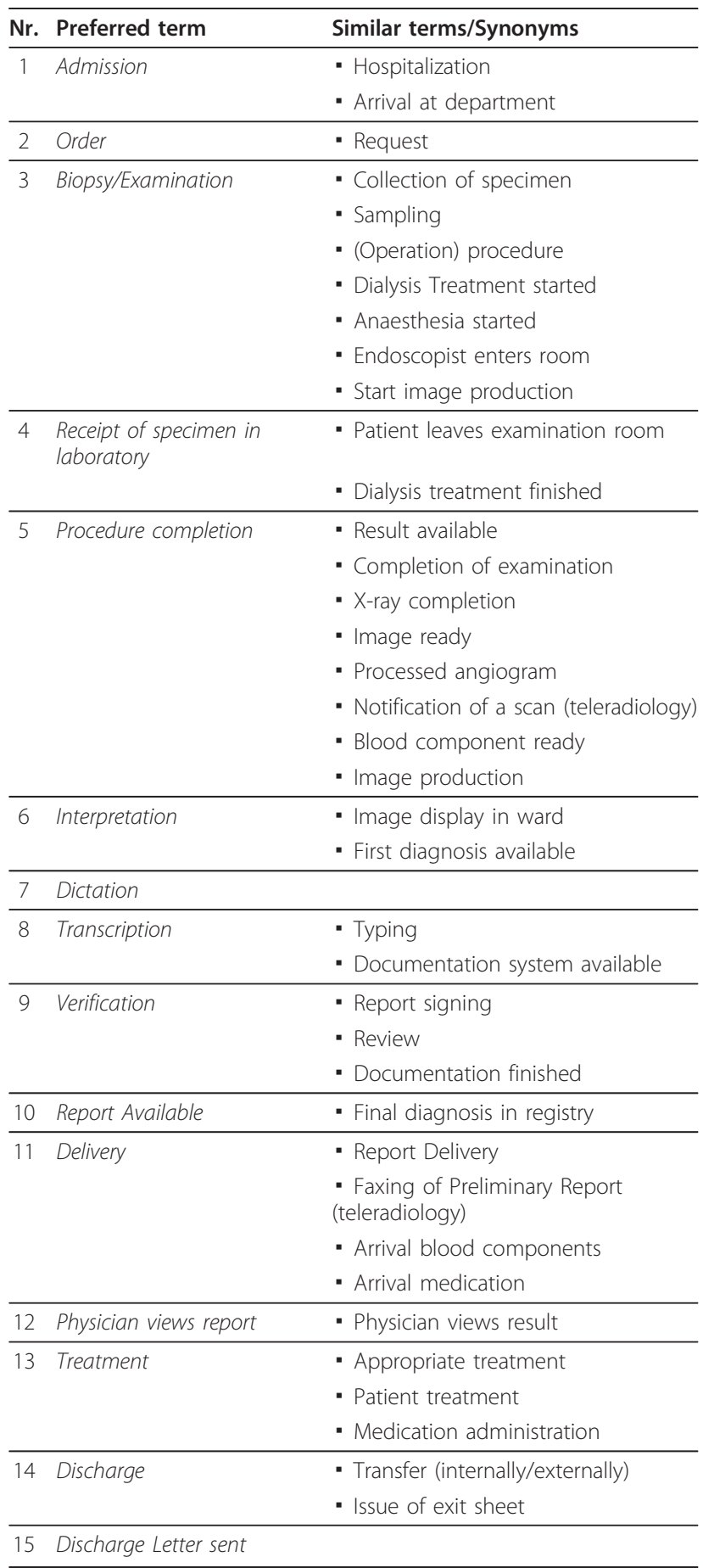

The table shows preferred terms and their synonyms for 15 points in time. They were identified through a consensus process while analysing starting and end points of the reviewed TAT definitions. These terms were used to illustrate the definitions on a generic timeline.

laboratory and nearly all references contained the interval between the receipt and the availability of the results. The points in time "interpretation", "dictation" and "transcription" were not covered.

\section{Domain "Radiology"}

In the radiology domain 11 different time intervals were found in our literature review. The most common definition was report TAT, which was measured from the $\mathrm{X}$-ray completion until the availability of the radiology report in the HIS (10 articles). Four of these definitions concerned dictation-, typing- and signing-process, which ranged from X-ray completion until delivery of results (6 papers). The next frequent TAT definition was from radiology request to $\mathrm{X}$-ray completion (5 papers). Three papers defined a TAT from radiology request to the availability of the report. Time intervals concerning the viewing of results or the following treatment were found in none of the analysed papers.

\section{Domain "Whole Clinic and others"}

This domain contains emergency department, medication and processes covering the whole clinic. We identified 21 different TAT definitions, of which the most commonly used ( 5 articles) spanned the entire stay in a hospital from admission to discharge or transfer. All other definitions were only used in one or two articles and addressed processes in different clinical departments.

When comparing Figures 2, 3 and 4, it becomes evident that some definitions from the laboratory and radiology domain with the same starting and end points were used in a large number of publications (e.g. "time from the receipt to the availability of results" used in 25 studies). Such frequently used definitions, suited for comparative process analyses and benchmarking, could not be found in other domains

\section{Discussion}

This review shows that TAT can be understood and measured in many different ways. In the laboratory domain, for example, the need to extend the early TAT definitions has existed since 1994, when Friedmann introduced the term "laboratory information float" to include the time when the result is available for the treating physician [146]. TAT is not a standardised measure and our results clearly show that there are many different time intervals, which all claim to be a TAT. There are also time intervals with the same starting and end points but all have different names. For benchmarking and optimisation of clinical processes the same understanding of TATs is crucial. Therefore, a consensus about these terms is necessary and should be agreed upon. Based on our review we propose the following definitions as described in table 2.

For the laboratory domain a similar approach to achieve a consensus was proposed by Ervasti et al., who emphasize the importance of the whole process and define TAT from a patient's point of view [147]. By introducing six TAT concepts based on four points in time (arrival, order, receipt, and report availability), the 


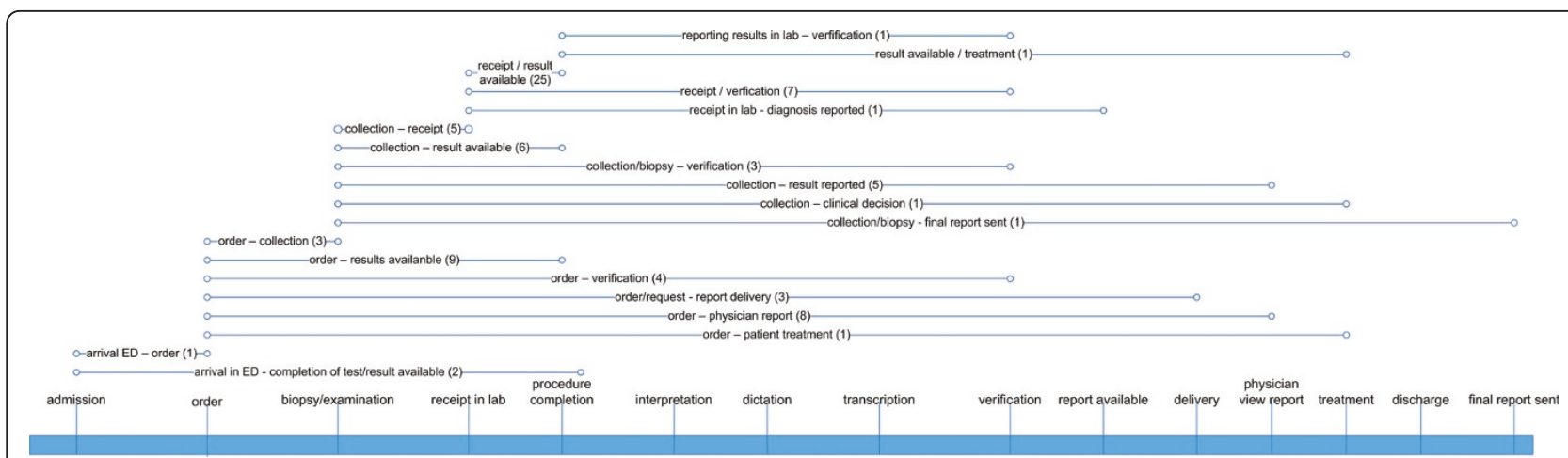

Figure 2 Turnaround time definitions in the laboratory domain. All identified definitions are illustrated with their starting and end points on a generic timeline. The number in brackets shows the number of papers in which the respective definition was used.

authors differentiate between the diagnostic TAT (arrival-to-report), the clinical TAT (arrival-to-order) and the laboratory TAT (order-to-report).

The measurement of TATs varies as much as their definitions. One study drew the data directly from their LIS [148] and thus used solely electronically available points in time. Process times can also be measured by shadowing medical staff and recording each working activity [149]. These different methods can result in different times and thus comparability between different studies is limited.

During our review of TATs we identified that times were measured in different units ranging from seconds to minutes to hours to days. Comparing different articles we found that the same definitions were measured in different units. As it did not seem relevant for our purpose we did not further evaluate these time units.

The idea of an abstract process is described by Kujala et al. who compare a patient episode with a customer order-to-delivery chain in industry [150]. Sinreich described a unified process chart from hospitalisation until discharge in 56 steps and defines 96 patient TATs to identify processes with major waiting times [151].
Other studies only focus on a few important points in time, which are then defined as milestones to describe relevant processes and time intervals [152]. In our approach to summarise TAT, we selected 15 points in time to represent the identified starting and end points on a level of details which covers all important aspects of the different clinical domains and provides a unified view on these clinical processes.

\section{Further observation}

While collecting relevant literature, we noticed that the number of published papers in a specific domain was somehow connected with the period of publication. Through our search strategy we found only five papers between 1971 and 1992. During the late 90s the publication rate goes up to five papers per year on average. Until 2004 it further increases to over 10 papers per year. With an unexpected big peak in 2005 of 22 papers and a down of only four papers in 2006 the rate continuously increases to about 12 papers per year on average at the end of our observation period in 2010. Before the year 2000 most of the papers were published in the laboratory domain. Until the end of 2009 the laboratory

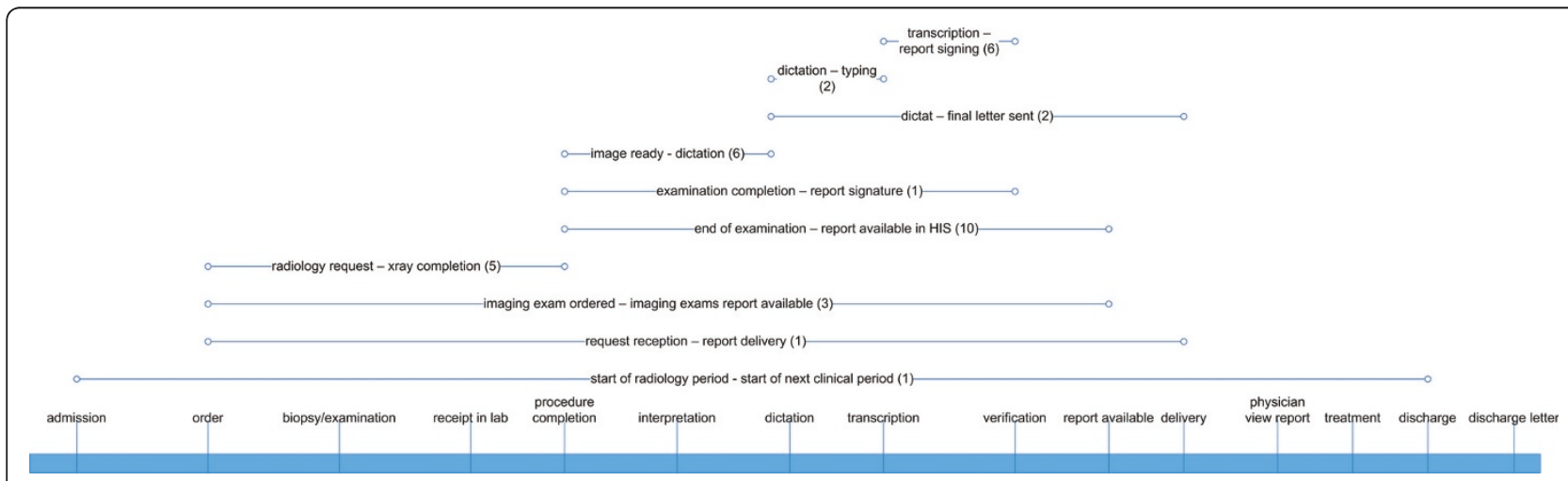

Figure 3 Turnaround time definitions in the radiology domain. All identified definitions are illustrated with their starting and end points on a generic timeline. The number in brackets shows the number of papers in which the respective definition was used. 


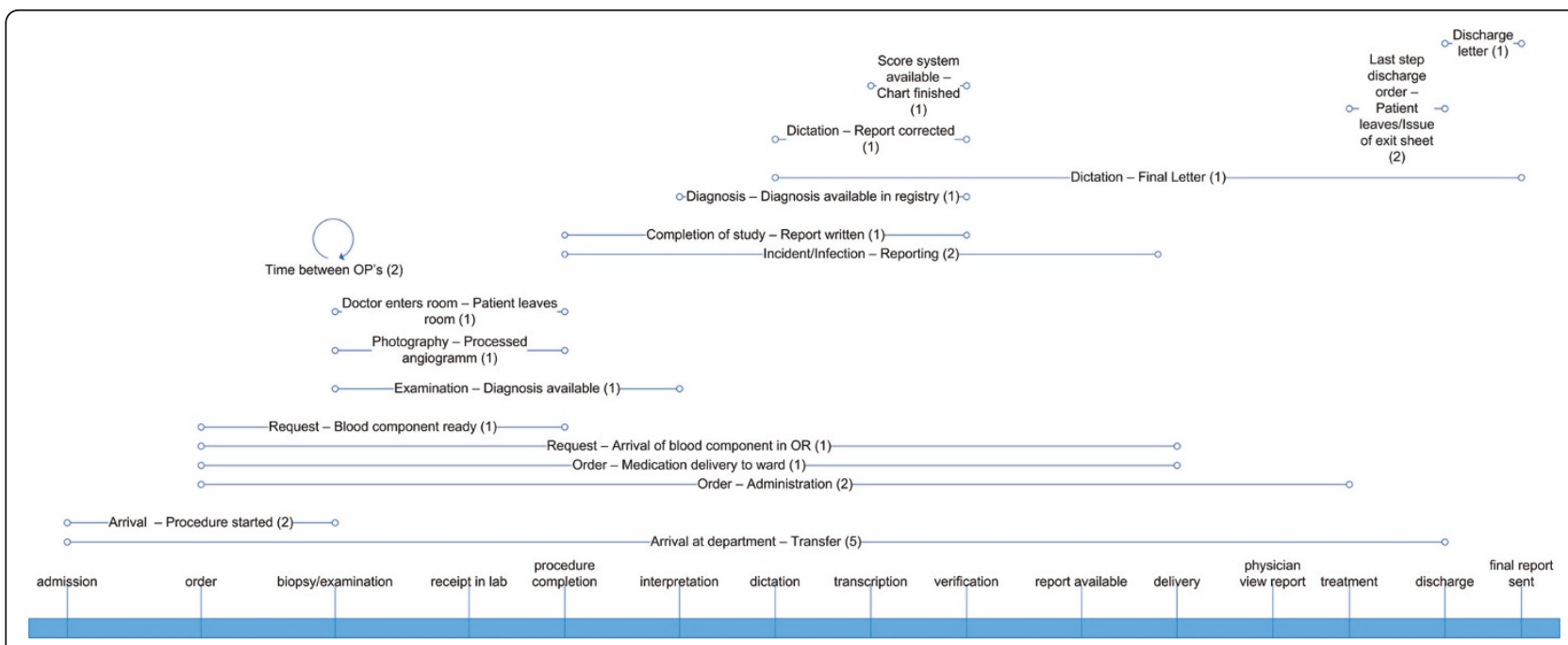

Figure 4 Turnaround time definitions in the whole clinic and all other domains. All identified definitions are illustrated with their starting and end points on a generic timeline. The number in brackets shows the number of papers in which the respective definition was used.

domain is still the most prominent one (about $45 \%$ of all published papers). Radiology and whole clinic, both started to become significant around the year 2000 and produce a similar amount of papers per year on average. Their publication rate is a little lower than the rate of the laboratory domain. Regarding Medication and Emergency Department the total number of published papers is relatively low.

Despite the focus on specific clinical domains in most papers there are also studies regardless of the domain like Mechanic et al., who from 1989 - 1998 analysed the time spent in general at a physician's office [153]. It also became evident that process times are often defined for clinical routine only, but it is equally important to measure the effects in clinical research such as time for patient recruitment in clinical trials [154]. As clinical processes are becoming more and more comprehensive, publications in this area might increase in the coming years.

An important aspect that arises during the analysis of TAT is to clarify the purpose behind measuring or optimizing process times, for which there are different motivations. The most common background and motivation is to reduce the waiting time for patients, so that the treatment can be started earlier or the patient can be discharged earlier. Sometimes this can decrease costs for the hospital due to reduced redundant work and process streamlining [2].

Some authors focus their analysis of timelines on physician satisfaction [155], whereas others concentrate on the cost saving aspect [34]. A different approach is suggested by Holland et al., who argue that the TAT outlier percentage is a better method of benchmarking laboratory performance $[156,157]$.

TAT are also commonly used to evaluate changes in certain processes (e.g. organizational changes, implementation of new information systems) by measuring the time needed before and after the intervention. However, it is difficult to directly compare these results, because of differences in the processes.

Other studies mentioned TAT changes as side effects. For example, Zardawi analysed the implementation of a quality assurance system that is primarily designed to reduce errors but they also found a reduction of TAT, even though it was not their main objective [158]. Also Ondategui-Parra et al. did not primarily analyse process indicators, but they put their emphasis on quality indicators like customer satisfaction [159].

Table 2 Proposed turnaround time definitions

\begin{tabular}{lllll}
\hline Abbr. & Long text & Start & End & Description \\
\hline TAT & Turnaround time & & & Generic term for clinical processes \\
\hline LTAT & Laboratory turnaround time & Receipt of specimen & Results available & Specific term for laboratorial processes \\
\hline MTAT & Medication turnaround time & Request & Patient delivery & Includes drug turnaround time, and pharmacy turnaround time \\
\hline ITAT & Imaging turnaround time & Request & Images available & Specific term for processes concerning images \\
\hline RTAT & Report turnaround time & Request & Report available & Generic term for processes concerning all types of reports \\
\hline TTAT & Total turnaround time & Request & Results available & Generic term for all kinds of hospital processes \\
\hline
\end{tabular}

This table proposes domain-specific and generic terms for TAT with defined starting and end points. 
Process times should not be the primary focus while analysing the quality of patient treatment. Yu and Gupta for example point out that the speed of analysing and reporting is not directly related to the quality of the interpretation [160]. Bewtra states that instead of further reducing TAT, a reasonable limit should be agreed on, because often patients do not benefit from the reduced TAT and it may even have negative effects on quality, teaching needs and the welfare of laboratory personnel [161].

\section{Limitations and strengths}

While extracting the different TAT definitions we did not consider the context and the underlying research questions of the respective articles in detail. Although we know that this is relevant, a discussion with regard to content need to be based on consistent definitions. As there are a lot of different points in time that may all be relevant in certain studies, it is evident that there are also different TAT definitions. Nevertheless, a classification through standardised wording, the use of existing definitions and the awareness that TAT may not be a well-defined measure can contribute towards better comparability.

The main purpose of TAT is to describe workflows and perform quantitative analyses of processes. In this review we identified 162 TAT definitions which were used for different purposes. Some TATs are not precisely defined and many researchers do not use existing definitions while measuring their own workflows. This makes a comparison of processes very difficult. The illustration of different definitions on a generic timeline may help to categorize own research questions. The proposed generic terms makes it easier to differentiate between processes and sub-processes.

\section{Conclusion}

Although measuring TAT is a common method when analysing clinical process times, it is difficult to compare studies, because there are many different definitions in use. In laboratory and radiology a considerable number of studies apply comparable TAT definitions. The mapping of TAT definitions to a generic timeline in order to facilitate benchmarking is feasible.

\section{Additional material}

Additional file 1: TAT Definitions. This file contains the full table with all TAT definitions and their references.

\section{Abbreviations}

CPOE: Computerised physician order entry; HIS: Hospital information system; ITAT: Imaging turnaround time; LTAT: Laboratory turnaround time; MTAT: Medication turnaround time; RTAT: Report turnaround time; TAT: Turnaround time; TTAT: Total turnaround time;

\section{Acknowledgements}

We acknowledge support by Deutsche Forschungsgemeinschaft and Open Access Publication Fund of University of Muenster.

\section{Authors' contributions}

$\mathrm{BB}, \mathrm{FF}$ and VT collected literature, summarized TAT definitions and wrote the manuscript. MD critically revised the manuscript. All authors read and approved the final manuscript.

\section{Competing interests}

The authors declare that they have no competing interests.

Received: 23 February 2011 Accepted: 24 May 2011

Published: 24 May 2011

\section{References}

1. Ammenwerth E, Ehlers F, Eichstädter R, Haux R, Pohl U, Resch F: Systems analysis in health care: framework and example. Methods Inf Med 2002, 41(2):134-40.

2. Lenz R, Buessecker F, Herlofsen H, Hinrichs F, Zeiler T, Kuhn KA: Demand driven Evolution of IT Systems in Healthcare. Methods Inf Med 2005, 44(1):4-10.

3. Bloch DM: Computer-generated management tools for the clinical pathology laboratory. II. Computer-generated graphic work flow. J Med Syst 1982, 6(3):305-10.

4. Tell R, Hoffman I: The elimination of turnaround time in routine ECG processing. J Electrocardiol 1971, 4(3):279-81.

5. Hawkins RC: Laboratory turnaround time. Clin Biochem Rev 2007, 28(4):179-94.

6. Braddock $\mathrm{CH}$, Snyder L: The Doctor Will See You Shortly The Ethical Significance of Time for the Patient-Physician Relationship. J Gen Intern Med 2005, 20(11):1057-62.

7. Hurlen $\mathrm{P}$, Ostbye $\mathrm{T}$, Borthne A, Gulbrandsen P: Introducing PACS to the Late Majority. A Longitudinal Study. J Digit Imaging 2010, 23(1):87-94.

8. Skibinski KA, White BA, Lin LI, Dong Y, Wu W: Effects of technological interventions on the safety of a medication-use system. Am J Health Syst Pharm 2007, 64(1):90-6.

9. Samaan ZM, Klein MD, Mansour ME, DeWitt TG: The impact of the electronic health record on an academic pediatric primary care center. $J$ Ambul Care Manage 2009, 32(3):180-7.

10. Westbrook Jl, Georgiou A, Rob Ml: Computerised order entry systems: sustained impact on laboratory efficiency and mortality rates? Stud Health Technol Inform 2008, 136:345-50.

11. Georgiou A, Williamson M, Westbrook Jl, Ray S: The impact of computerized physician order entry systems on pathology services: A systematic review. Int J Med Inform 2007, 76(7):514-29.

12. Lehman ML, Brill JH, Skarulis PC, Keller D, Lee C: Physician Order Entry impact on drug turn-around times. Proc AMIA Symp 2001, 359-363.

13. Cordero L, Kuehn L, Kumar RR, Mekhjian HS: Impact of computerized physician order entry on clinical practice in a newborn intensive care unit. J Perinatol 2004, 24(2):88-93.

14. Manor PG: Turnaround times in the laboratory: a review of the literature. Clin Lab Sci 1999, 12(2):85-9.

15. Georgiou A, Westbrook Jl: Computerised Order Entry Systems and Pathology Services - A Synthesis of the Evidence. Clin Biochem Rev 2006, 27(2):79-87.

16. Georgiou A, Williamson M, Westbrook Jl, Ray S: The impact of computerised physician order entry systems on pathology services: A systematic review. Int J Med Inform 2007, 76(7):514-29.

17. Poissant L, Pereira J, Tamblyn R, Kawasumi $Y$ : The Impact of Electronic Health Records on Time Efficiency of Physicians and Nurses: A Systematic Review. J Am Med Inform Assoc 2005, 12(5):505-16.

18. Schimke I: Quality and timeliness in medical laboratory testing. Anal Bioanal Chem 2009, 393(5):1499-504.

19. Pirnejad H, Berg M, Aarts J: The impact of computerized provider order entry systems on inpatient clinical workflow: a literature review. J Am Med Inform Assoc 2009, 16(4):539-49.

20. Lewandrowski K: How the clinical laboratory and the emergency department can work together to move patients through quickly. Clin Leadersh Manag Rev 2004, 18(3):155-9. 
21. Mastrovitch TA, Bithoney WG, DeBari VA, Nina AG: Point-of-care testing for drugs of abuse in an urban emergency department. Ann Clin Lab Sci 2002, 32(4):383-6.

22. Pubmed. [http://www.ncbi.nlm.nih.gov/pubmed/], (last access 01.04.2011).

23. Ramaswamy MR, Chaljub G, Esch O, Fanning DD, vanSonnenberg E: Continuous speech recognition in MR imaging reporting: advantages, disadvantages, and impact. AJR Am J Roentgenol 2000, 174(3):617-22.

24. Adams R, Warner P, Hubbard B, Goulding T: Decreasing turnaround time between general surgery cases: a six sigma initiative. J Nurs Adm 2004, 34(3):140-148.

25. Ajami S, Ketabi S: An analysis of the average waiting time during the patient discharge process at Kashani Hospital in Esfahan, Iran: a case study. HIM J 2007, 36(2):37-42.

26. Alquist M, Hegbrant JB, Bosch JP: Monitor Turnaround Time and Time Efficiency in Hemodialysis Delivery - A Global Comparison. Blood Purif 2009, 28(3):234-238.

27. Amarasingham R, Plantinga L, Diener-West M, Gaskin DJ, Powe NR: Clinical information technologies and inpatient outcomes: a multiple hospital study. Arch Intern Med 2009, 169(2):108-14.

28. Andriole KP, Avrin DE, Weber E, Luth DM, Bazzill TM: Automated examination notification of emergency department images in a picture archiving and communication system. J Digit Imaging 2001, 117(9):900-5.

29. Berg B, Denton B, Nelson H, Balasubramanian H, Rahman A, Bailey A, Lindor K: A Discrete Event Simulation Model to Evaluate Operational Performance of a Colonoscopy Suite. Med Decis Making 2009.

30. Bilwani F, Siddiqui I, Vaqar S: Determination of delay in turn around time (TAT) of stat tests and its causes: an AKUH experience. J Pak Med Assoc 2003, 40(8):1628-30.

31. Bloch DM: Computer-Generated Management Tools for Clinical Pathology Laboratory. J Med Syst 1980, 163(6):1503-7.

32. Bowie P, Dougall A, Brown R, Marshall D: Turnaround time of in-patient discharge letters: a simple system of audit. Health Bull (Edinb) 1996, 119(10):943-7.

33. Breil B, Semjonow S, Dugas M: HIS-based electronic documentation can significantly reduce the time from biopsy to final report for prostate tumours and supports quality management as well as clinical research. BMC Med Inform Decis Mak 2009, 54(6):438-40.

34. Breslow MJ, Rosenfeld BA, Doerfler M, Burke G, Yates G, Stone DJ, Tomaszewicz P, Hochman R, Plocher DW: Effect of a multiple-site intesive care unit telemdicine program on clinical and economic outcomes. Crit Care Med 2004, 1(2):70-4.

35. Bruins $M$, Oord H, Bloembergen P, Wolfhagen M, Casparie A, Degener J, Ruijs G: Lack of effect of shorter turnaround time of microbiological procedures on clinical outcomes: a randomised controlled trial among hospitalised patients in the Netherlands. Eur J Clin Microbiol Infect Dis 2005, 248(1):65-72.

36. Bürkle T, Beisig A, Ganslmayer M, Prokosch HU: A Randomized Controlled Trial to Evaluate an Electronic Scoring Tool in the ICU. Stud Health Technol Inform 2008, 1(6):301-6.

37. Carraro P, Plebani M: Process control reduces the laboratory turnaround time. Clin Chem Lab Med 2002, 120(3):234-44.

38. Chaudhry B, Wang J, Wu S, Maglione M, Mojica W, Roth E, Morton SC, Shekelle PG: Systematic Review: Impact of Health Information Technology on Quality, Efficiency and Costs of Medical Care. Ann Intern Med 2006, 21(2):107-17.

39. Chien TI, Lu JY, Kao JT, Cheng YC, Lee YF: Evaluation and Improvement Strategy of Analytical Turnaround Time in the Stat Laboratory. J Formos Med Assoc 2007, 168(4):889-93.

40. Choplin RH, Boehme JM, Cowan RJ, Gelfand DW, Maynard CD, Park WC Jr, Volberg FM, Williams RC: A computer-assisted radiologic reporting system. Radiology 1984, 121(10):1031-41.

41. Coard KC, Gibson TN: Turnaround time in the surgical pathology laboratory. West Indian Med J 1999, 108(4):400-5.

42. Collinson PO, John C, Lynch S, Rao A, Canepa-Anson R, Carson E, Cramp D: A prospective randomized controlled trial of point-of-care testing on the coronary care unit. Ann Clin Biochem 2004, 44(8 Pt 1):1597-603.

43. Cordero L, Kuehn L, Kumar RR, Mekhjian HS: Impact of computerized physician order entry on clinical practice in a newborn intensive care unit. J Perinato/ 2004, 5(8):533-8.
44. Crabbe JP, Frank CL, Nye WW: Improving report turnaround time: an integrated method using data from a radiology information system. AJR Am J Roentgenol 1994, 36(11):867-70.

45. DeFlorio R, Coughlin B, Coughlin R, Li H, Santoro J, Akey B, Favreau M: Process modification and emergency department radiology service. Emerg Radiol 2008, 11(3 Suppl 1):149-50.

46. Dhatt G, Manna J, Bishawi B, Chetty D, Al Sheiban A, James D: Impact of a satellite laboratory on turnaround times for the emergency department. Clin Chem Lab Med 2008, 10(3):241-5.

47. Di Bartolomeo S, Valent F, Rosolen V, Sanson G, Nardi G, Cancellieri F, Barbone F: Are pre-hospital time and emergency department disposition time useful process indicators for trauma care in Italy? Injury 2007, 48(2):85-7.

48. Di Serio F, Lovero R, Leone M, De Sario R, Ruggieri V, Varraso L, Pansini N: Integration between the tele-cardiology unit and the central laboratory: methodological and clinical evaluation of point-of-care testing cardiac marker in the ambulance. Clin Chem Lab Med 2006, 15(3-4):197-204.

49. Dugas $\mathrm{M}$, Eckholt $\mathrm{M}$, Bunzemeier $\mathrm{H}$ : Benchmarking of hospital information systems: Monitoring of discharge letters and scheduling can reveal heterogeneities and time trends. MC Med Inform Decis Mak 2008, 12 (2 Suppl 1):166-7.

50. Ervasti M, Penttilä K, Siltari S, Delezuch W, Punnonen K: Diagnostic, clinical and laboratory turnaround times in troponin T testing. Clin Chem Lab Med 2008, 46(7):1030-2.

51. Fernandes CM, Worster A, Eva K, Hill S, McCallum C: Pneumatic tube delivery system for blood samples reduces turnaround times without affecting sample quality. J Emerg Nurs 2006, 6(6):512-22.

52. Fernandes CM, Worster A, Hill S, McCallum C, Eva K: Root cause analysis of laboratory turnaround times for patients in the emergency department. CJEM 2004, 12(2):85-9.

53. Fitch JC, Mirto GP, Geary KL, Byrne DW, Hines RL: Point-of-care and standard laboratory coagulation testing during cardiovascular surgery: balancing reliability and timeliness. J Clin Monit Comput 1999, 68:610-3.

54. Fleisher M, Schwartz MK: Strategies of organization and service for the critical-care laboratory. Clin Chem 1990, 45(8 Pt 1):1168-75.

55. Galloway M, Nadin L: Benchmarking and the laboratory. J Clin Pathol 2001, 123(7):607-14.

56. Georgiou A, Westbrook J: Computerised Order Entry Systems and Pathology Services - A Synthesis of the Evidence. Clin Biochem Rev 2006 13(2 Suppl 1):153-4.

57. Georgiou A, Williamson M, Westbrook Jl, Ray S: The impact of computerised physician order entry systems on pathology services: A systematic review. Int J Med Inform 2007, 26(6):361-73.

58. Giberson RT, Austin RL, Charlesworth J, Adamson G, Herrera GA: Microwave and digital imaging technology reduce turnaround times for diagnostic electron microscopy. Ultrastruct Pathol 2003, 13(2 Suppl 1):105-7.

59. Green M: Successful alternatives to alternate site testing. Use of a pneumatic tube system to the central laboratory. Arch Pathol Lab Med 1995, 46(5):751-6.

60. Guss DA, Chan TC, Killeen JP: The impact of a pneumatic tube and computerized physician order management on laboratory turnaround time. Ann Emerg Med 2008, 13(4):175-7.

61. Haglund S, Transö B, Persson LG, Zafirova T, Grodzinsky E: Fast laboratory test results alone cannot deliver the benefits of near patient testing: a follow-up study after 3 years of extended laboratory service at a primary health care centre. J Eval Clin Pract 2009, 14(2 Suppl 1):143-4.

62. Halsted MJ, Froehle CM: Design, implementation, and assessment of a radiology workflow management system. AJR Am J Roentgenol 2008, 54(8):590-7.

63. Hawker CD, Roberts WL, Garr SB, Hamilton LT, Penrose JR, Ashwood ER, Weiss RL: Automated transport and sorting system in a large reference laboratory: part 2. Implementation of the system and performance measures over three years. Clin Chem 2002, 14(3):149-57.

64. Hayt DB, Alexander S: The pros and cons of implementing PACS and speech recognition systems. J Digit Imaging 2001, 116(3):311-5.

65. Henricks WH, Roumina K, Skilton BE, Ozan DJ, Goss GR: The utility and cost effectiveness of voice recognition technology in surgical pathology. Mod Pathol 2002

66. Howanitz JH, Howanitz PJ: Laboratory results. Timeliness as a quality attribute and strategy. Am J Clin Pathol 2001, 125(7):863-71. 
67. Huang YW, Chen WH, Wu HJ, Chien HY, Lin TY, Chiang HH, Huang TM, Lin CL: Learning Curve of a New Hospital Laboratory. The Monitoring Computer-Generated Turnaround Time of Laboratory Tests in Emergency Department. Clin Chem Lab Med 2003, 19(4):295-8.

68. Hurlen P, Østbye T, Borthne A, Gulbrandsen P: Introducing PACS to the Late Majority. A Longitudinal Study. J Digit Imaging 2008, 40(4):421-2.

69. Jackson PE, Langlois Sle P: Introduction of picture archiving and communication system at The Townsville Hospital. Australas Radiol 2005, 48(10):1761-7.

70. James D, Hess S, Kretzing JE Jr, Stabile ME: Showing what right looks likehow to improve performance through a paradigm shift around implementation thinking. J Healthc Inf Manag 2007, 15(5):565-71.

71. Jones BA, Novis DA: Nongynecologic cytology turnaround time: a College of American Pathologists Q-Probes study of 180 laboratories. Arch Pathol Lab Med 2001, 125(10):1279-84.

72. Kalyanpur A, Weinberg J, Neklesa V, Brink JA, Forman HP: Emergency radiology coverage: technical and clinical feasibility of an international teleradiology model. Emerg Radiol 2003, 15(Suppl 1):234-6.

73. Kedar I, Ternullo JL, Weinrib CE, Kelleher KM, Brandling-Bennett H, Kvedar JC: Internet based consultations to transfer knowledge for patients requiring specialised care: retrospective case review. BMJ 2003, 9(5):529-39.

74. Kilgore ML, Steindel SJ, Smith JA: Evaluating stat testing options in an academic health center: therapeutic turnaround time and staff satisfaction. Clin Chem 1998, 126(8):909-14.

75. Kost GJ, Tran NK: Point-of-Care Testing and Cardiac Biomarkers: The Standard of Care and Vision for Chest Pain Centers. Cardiol Clin 2005, 118(4):527-33.

76. Kropp S, Andreis C, te Wildt B, Reulbach U, OhImeier M, Auffarth I, Ziegenbein M: Psychiatric patients turnaround times in the emergency department. Clin Pract Epidemol Ment Health 2005, 8(3):333-41.

77. Krupinski EA, McNeill K, Ovitt TW, Alden S, Holcomb M: Patterns of use and satisfaction with a university-based teleradiology system. J Digit Imaging 1999, 126(1):11-8.

78. Kuperman GJ, Teich JM, Tanasijevic MJ, Maluf N, Rittenberg E, Jha A, Fiskio J, Winkelmann J, Bates DW: Improving response to critical laboratory results with automation_results of a randomized controlled trial. J Am Med Inform Assoc 1999, 53(2):65-7.

79. Langer GS: Impact of tightly coupled PACS/speech recognition on report turnaround time in the radiology department. J Digit Imaging 2002, 27(3):187-96.

80. Lee JK, Renner JB, Saunders BF, Stamford PP, Bickford TR, Johnston RE, Hsaio HS, Phillips ML: Effect of real-time teleradiology on the practice of the emergency department physician in a rural setting: initial experience. Acad Radiol 1998, 41(10):1373-8

81. Lee-Lewandrowski E, Corboy D, Lewandrowski K, Sinclair J, McDermot S, Benzer TI: Implementation of a point-of-care satellite laboratory in the emergency department of an academic medical center. Impact on test turnaround time and patient emergency department length of stay. Arch Pathol Lab Med 2003, 10(3):115-8.

82. Lehman ML, Brill JH, Skarulis PC, Keller D, Lee C: Physician Order Entry Impact on Drug Turnaround Times. Proc AMIA Symp 2001, 326(7391):359-63.

83. Lemme PJ, Morin RL: The implementation of speech recognition in an electronic radiology practice. J Digit Imaging 2000, 127(4):456-60.

84. Lepanto L: Impact of Electronic Signature on Radiology Report Turnaround Time. J Digit Imaging 2003, 16(3):306-9.

85. Lepanto L, Paré G, Gauvin A: Impact of PACS deployment strategy on dictation turnaround time of chest radiographs. Acad Radiol 2006 18(3):178-82.

86. Lepanto L, Pare' G, Aubry D, Robillard P, Lesage J: Impact of PACS on Dictation Turnaround Time and Productivity. J Digit Imaging 2006, 26(1):23-6.

87. Maass $\mathrm{G}$, Cortezzo M: Computerizing incident reporting at a community hospital. Jt Comm J Qual Improv 2000, 25(3):42-9.

88. Manor PG: Turnaround times in the laboratory: A review of the literature. Clin Lab Sci 1999, 127(11):1421-3.

89. Mehta A, Dreyer K, Boland G, Frank M: Do picture archiving and communication systems improve report turnaround times? J Digit Imaging 2000, 10(1):27-30.
90. Mehta A, McLoud TC: Voice recognition. J Thorac Imaging 2003, 34(3):140-8.

91. Mekhjian HS, Kumar RR, Kuehn L, Bentley TD, Teater P, Thomas A, Payne B, Ahmad A: Immediate Benefits Realized following Implementation of Physician Order Entry at an Academic Medical Center. J Am Med Inform Assoc 2002, 32(1):31-8.

92. Meyer MA, Seim AR, Fairbrother P, Egan MT, Sandberg WS: Automatic time-motion study of a multistep preoperative process. Anesthesiology 2008, 41(Pt 5):397-404

93. Mitchell L, Archer E, Middleton S, Maclean A, Jones L, Benger J, Lloyd G: Paediatric distal radial fracture manipulation: multicentre analysis of process times. Emerg Med J 2009, 24(2):88-93.

94. Mitchell L: Benchmarking, benchmarks, or best practices? Applying quality improvement principles to decrease surgical turnaround time. Best Pract Benchmarking Healthc 1996, 6(2):116-22.

95. Morales AR, Nadji M, Livingstone AS: Rapid-response, molecular-friendly surgical pathology: a radical departure from the century-old routine practice. J Am Coll Surg 2008, Arch Pathol Lab Med. 2004 Feb.128(2): 15864.

96. Morgan MB, Branstetter BF, Lionetti DM, Richardson JS, Chang PJ: The radiology digital dashboard: effects on report turnaround time. J Digit Imaging 2008, 38(6):548-51.

97. Murray P: Applying quality management tools to medical photography services: a pilot project. J Audiov Media Med 2003, 24(5):305-13.

98. Negri M, Carraro P, Caenaro G, Cappelletti P, Giavarina D, Mezzena G, Prandini B, Rampoldi E, Siviero F: External Quality Assessment of stat test intralaboratory turnaround times. Pilot study from the Members of the Working Group for the Standardization and Promotion of Turnaround Time Control under the Auspices of the Comitato Italiano per la Standardizzazione dei Metodi Ematologici e di Laboratorio. Clin Chem Lab Med 1998, 49(4):278-82.

99. Niazkhani Z, Pirnejad H, Berg M, Aarts J: The impact of computerized provider order entry systems on inpatient clinical workflow: a literature review. J Am Med Inform Assoc 2009, 16(4):539-49.

100. Nitrosi A, Borasi G, Nicoli F, Modigliani G, Botti A, Bertolini M, Notari P: A filmless radiology department in a full digital regional hospital: quantitative evaluation of the increased quality and efficiency. J Digit Imaging 2007, 23(4):467-90, vi.

101. Novis DA, Friedberg RC, Renner SW, Meier FA, Walsh MK: Operating room blood delivery turnaround time. Arch Pathol Lab Med 2002, 01:27.

102. Novis DA, Jones BA, Dale JC, Walsh MK: College of American Pathologists. Biochemical markers of myocardial injury test turnaround time: a College of American Pathologists Q-Probes study of 7020 troponin and 4368 creatine kinase-MB determinations in 159 institutions. Arch Pathol Lab Med 16(4):449-54.

103. Ondategui-Parra S, Erturk S, Ross P: Survey of the Use of Quality Indicators in Academic Radiology Departments. AJR Am J Roentgenol 2006, 330(7503):1309-13.

104. Ostbye T, Moen A, Erikssen G, Hurlen P: Introducing a module for laboratory test order entry and reporting of results at a hospital ward: an evaluation study using a multi-method approach. J Med Syst 1997, 2(6):478-84.

105. Pelegrí MD, García-Beltrán L, Pascual C: Improvement of emergency and routine turnaround time by data processing and instrumentation changes. Clin Chim Acta 1996, 144(10):742-52.

106. Pellar TG, Ward PJ, Tuckerman JF, Henderson AR: The freckle plot (daily turnaround time chart): a technique for timely and effective quality improvement of test turnaround times. Clin Chem 1993, 44(6):768-73.

107. Persoon TJ, Zaleski S, Cohen MB: Improving Pap Test Turnaround Time Using External Benchmark Data and Engineering Process Improvement Tools. Am J Clin Pathol 2002, 32(2):139-43.

108. Pines JM, Hollander JE, Localio AR, Metlay JP: The association between emergency department crowding and hospital performance on antibiotic timing for pneumonia and percutaneous intervention for myocardial infarction. Acad Emerg Med 2006, 27(2):79-87.

109. Prijatelj V, Vuckovic A, Cerne D: The optimization of turnaround time for blood samples in an emergency clinical laboratory. Stud Health Technol Inform 1999, 76(7):514-29.

110. Raab SS, Grzybicki DM, Condel JL, Stewart WR, Turcsanyi BD, Mahood LK, Becich MJ: Effect of Lean method implementation in the histopathology 
section of an anatomical pathology laboratory. J Clin Pathol 2008, 13(4):447-52.

111. Reiner Bl, Siegel EL, Hooper F, Protopapas Z: Impact of filmless imaging on the frequency of clinician review of radiology images. J Digit Imaging 1998, 19(1):92-7

112. Ribé A, Ribalta T, Lledó R, Torras G, Asenjo MA, Cardesa A: Evaluation of turnaround times as a component of quality assurance in surgical pathology. Int I Qual Health Care 1998, 187(5):W451-5.

113. Rollo $J$, Fauser BA: Computers in total quality management. Statistical process control to expedite stats. Arch Pathol Lab Med 1993, 13(8):873-8.

114. Rudat KS, Henry J, Mosley J: Improving laboratory results turnaround time. Best Pract Benchmarking Healthc 1996, 178(4):400-9.

115. Seaberg RS, Stallone RO, Statland BE: The role of total laboratory automation in a consolidated laboratory network. Clin Chem 2000, 59(5):533-6.

116. Seltzer SE, Kelly P, Adams DF, Chiango BF, Viera MA, Fener E, Hooton S, Bannon-Rohrbach S, Healy CD, Doubilet PM, Holman BL: Expediting the turnaround of radiology reports in a teaching hospital setting. AJR Am J Roentgenol 1997, 32(4):276-80.

117. Settakorn J, Kuakpaetoon T, Leong FJ, Thamprasert K, Ichijima K: Store-andforward diagnostic telepathology of small biopsies by e-mail attachment: a feasibility pilot study with a view for future application in Thailand diagnostic pathology services. Telemed J E Health 2002, 36(2):37-42.

118. Sferrella SM: Success with voice recognition. Radiol Manage 2003, 106(7):558-64.

119. Sheppard C, Franks N, Nolte F, Fantz C: Improving quality of patient care in an emergency department: a laboratory perspective. Am J Clin Pathol 2008, 38(3):305-11.

120. Smellie WS, Johnston J, Galloway PJ: Method for assessment of laboratory turnaround times: comparison before, during, and after analysis. J Clin Pathol 1994, 21(1):54-61.

121. Smith BJ, McNeely MDD: The Influence of an Expert System for Test Ordering and Interpretation on Laboratory Investigations. Clin Chem 1999, 21(1):50-8.

122. Smith-Gagen J, Cress RD, Drake CM, Felter MC, Beaumont JJ: Factors associated with time to availability for cases reported to populationbased cancer registries. Cancer Causes Control 2005, 20(2):140-8.

123. Steindel SJ, Howanitz PJ: Changes in emergency department turnaround time performance from 1990 to 1993. A comparison of two College of American Pathologists Q-probes studies. Arch Pathol Lab Med 1997, 136:279-84.

124. Steindel SJ, Howanitz PJ: Physician satisfaction and emergency department laboratory test turnaround time. Arch Pathol Lab Med 2001, 15(6):405-12.

125. Steindel SJ, Jones BA: Routine outpatient laboratory test turnaround times and practice patterns: a College of American Pathologists QProbes study. Arch Pathol Lab Med 2002, 46(10):1464-7.

126. Steindel SJ, Novis DA: Using outlier events to monitor test turnaround time. Arch Pathol Lab Med 1999, 08:15.

127. Storrow AB, Zhou C, Gaddis G, Han JH, Miller K, Klubert D, Laidig A, Aronsky D: Decreasing Lab Turnaround Time Improves Emergency Department Throughput and Decreases Emergency Medical Services Diversion: A Simulation Model. Acad Emerg Med 2008, 51(2):181-5.

128. Tornel PL, Ayuso E, Martinez P: Evaluation of the turnaround time of an integrated preanalytical and analytical automated modular system in a medium-sized laboratory. Clin Biochem 2005, 191(2):321-7.

129. Trumm CG, Glaser C, Paasche V, Crispin A, Popp P, Küttner B, Francke M, Nissen-Meyer S, Reiser M: Impact of a PACS/RIS-integrated speech recognition system on radiology reporting time and report availability. Rofo 2006.

130. Twair AA, Torreggiani WC, Mahmud SM, Ramesh N, Hogan B: Significant savings in radiologic report turnaround time after implementation of a complete picture archiving and communication system (PACS). J Digit Imaging 2000, 108(6):1109-16

131. Valenstein P, Walsh M: Five-Year Follow-up of Routine Outpatient Test. Arch Pathol Lab Med 2003, 207(3):320-5.

132. Van Arsdale RW, Schad R: Evaluation of a facsimile (fax) transfer system for medication order delivery. Hosp Pharm 1991, 61(11):1193-9.

133. von Plessen C, Aslaksen A: Improving the quality of palliative care for ambulatory patients with lung cancer. BMJ 2005, 130(4):573-7.
134. Ward M, Brandsema P, van Straten E, Bosman A: Electronic reporting improves timeliness and completeness of infectious disease notification. Euro Surveill 2005, 15(11):1130-5.

135. Westbrook Jl, Georgiou A, Dimos A, Germanos T: Computerised pathology test order entry reduces laboratory turnaround times and influences tests ordered by hospital clinicians: a controlled before and after study. J Clin Pathol 2006, 136:345-50.

136. Westbrook JI, Georgiou A, Lam M: Does Computerised Provider Order Entry Reduce Test Turnaround Times? A Before-and-After Study at Four Hospitals. Stud Health Technol Inform 2009, 28(3):234-238.

137. Westbrook Jl, Georgiou A, Rob Ml: Computerised Order Entry Systems: Sustained Impact on Laboratory Efficiency and Mortality Rates? Stud Health Technol Inform 2008.

138. Westbrook Jl, Georgiou A, Rob Ml: Test Turnaround Times and Mortality Rates 12 and 24 Months after the Introduction of a Computerised Provider Order Entry System. Methods Inf Med 2009.

139. Wheeler S, Cassimus GC: Selecting and implementing a voice recognition system. Radiol Manage 1999.

140. Winkelman JW, Tanasijevic MJ, Wybenga DR, Otten J: How fast is fast enough for clinical laboratory turnaround time? Measurement of the interval between result entry and inquiries for reports. Am J Clin Pathol 1997.

141. Winkelman JW, Wybenga DR, Tanasijevic MJ: The fiscal consequences of central vs distributed testing of glucose. Clin Chem 1994, 09:05.

142. Wong WS, Roubal I, Jackson DB, Paik WN, Wong VK: Outsourced teleradiology imaging services: an analysis of discordant interpretation in 124, 870 cases. J Am Coll Radiol 2005, 15(2):227-33.

143. Worster A, Fernandes CM, Malcolmson C, Eva K, Simpson D: Identification of root causes for emergency diagnostic imaging delays at three Canadian hospitals. J Emerg Nurs 2006, 26(1):41-2.

144. Zarbo RJ, Gephardt GN, Howanitz PJ: Intralaboratory timeliness of surgical pathology reports. Results of two College of American Pathologists QProbes studies of biopsies and complex specimens. Arch Pathol Lab Med 1996, 150:527-31.

145. Zick RG, Olsen J: Voice recognition software versus a traditional transcription service for physician charting in the ED. Am J Emerg Med 2001, 48(2):211-5.

146. Friedman BA: The laboratory information float, time-based competition, and point-of-care testing. Clin Lab Manage Rev 1994, 8(5):509-13.

147. Ervasti M, Penttilä K, Siltari S, Delezuch W, Punnonen K: Diagnostic, clinical and laboratory turnaround times in troponin T testing. Clin Chem Lab Med 2008, 46(7):1030-2.

148. Pansini $\mathrm{N}$ : The national health system: future possibilities for the clinical laboratory. Clin Chim Acta 2002, 319(2):101-5.

149. Mache S, Scutaru C, Vitzthum K, Quarcoo K, Schöffel S, Welte T, Klapp BF, Groneberg DA: Does type of hospital ownership influence physicians' daily work? Hum Resour Health 2009, 7:41.

150. Kujala J, Lillrank P, Kronström V, Peltokorpi A: Time-based management of patient processes. J Health Organ Manag 2006, 20(6):512-24.

151. Sinreich D, Marmor Y: Ways to reduce patient turnaround time and improve service quality in emergency departments. J Health Organ Manag 2005, 19(2):88-105.

152. Sokal SM, Chang Y, Craft DL, Sandberg WS, Dunn PF, Berger DL: Surgeon profiling: a key to optimum operating room use. Arch Surg 2007, 142(4):365-70.

153. Mechanic D, McAlpine DD, Rosenthal M: Are Patients Office visits with physicians getting shorter? N Engl J Med 2001, 344(3):198-204.

154. Dugas M, Amler S, Lange M, Gerß J, Breil B, Köpcke W: Estimation of Patient Accrual Rates in Clinical Trials Based on Routine Data from Hospital Information Systems. Methods Inf Med 2009, 48(3):263-6.

155. Steindel SJ, Howanitz PJ: Changes in emergency department turnaround time performance from 1990 to 1993. A comparison of two College of American Pathologists Q-probes studies. Arch Pathol Lab Med 1997, 121(10):1031-41.

156. Holland LL, Smith LL, Blick KE: Reducing laboratory turnaround time outliers can reduce emergency department patient length of stay. Am J Clin Pathol 2005, 124(5):672-4.

157. Holland LL, Smith LL, Blick KE: Total laboratory automation can help eliminate the laboratory as a factor in emergency department length of stay. Am J Clin Pathol 2006, 125(5):765-70.

158. Zardawi IM, Bennett G, Jain S, Brown M: The role of peer review in internal quality assurance in cytopathology. Pathology 1998, 30(3):309-13. 
159. Ondategui-Parra S, Erturk SM, Ros PR: Survey of the use of quality indicators in academic radiology departments. AJR Am J Roentgenol 2006, 187(5):W451-5.

160. Yu GH, Gupta PK: The pathologic obsession with turnaround time in gynecologic cytology: is it warranted? Diagn Cytopathol 1998, 19(5):321-2.

161. Bewtra C: Cytology turnaround time: are we being too fast? Diagn Cytopathol 2003, 29(5):241-2.

\section{Pre-publication history}

The pre-publication history for this paper can be accessed here: http://www.biomedcentral.com/1472-6947/11/34/prepub

doi:10.1186/1472-6947-11-34

Cite this article as: Breil et al:: Mapping Turnaround Times (TAT) to a

Generic Timeline: A Systematic Review of TAT Definitions in Clinical

Domains. BMC Medical Informatics and Decision Making 2011 11:34.

\section{Submit your next manuscript to BioMed Central} and take full advantage of:

- Convenient online submission

- Thorough peer review

- No space constraints or color figure charges

- Immediate publication on acceptance

- Inclusion in PubMed, CAS, Scopus and Google Scholar

- Research which is freely available for redistribution

Submit your manuscript at www.biomedcentral.com/submit 